\title{
COMPARATIVE EVALUATION OF POWER AND TECHNOLOGICAL CHARACTERISTICS IN CONTINUOUS FLASH-BUTT WELDING OF THICK-WALLED PARTS AT DIRECT AND ALTERNATING CURRENT
}

\author{
S.I. KUCHUK-YATSENKO, P.M. RUDENKO, V.S. GAVRISH and K.V. GUSHCHIN \\ E.O. Paton Electric Welding Institute, NASU \\ 11 Bozhenko Str., 03680, Kiev, Ukraine. E-mail: office@paton.kiev.ua
}

\begin{abstract}
In the recent years the DC sources are widely applied in the equipment for flash-butt welding. At the same time there is a positive experience in AC application in such equipment. The aim of the present work consisted in comparative evaluation of power and technological characteristics of welding processes in using two power sources. The flash-butt welding of low-alloy steel plates of $25 \mathrm{~mm}$ thickness using continuous flashing was performed using AC and DC power sources. The influence of high-frequency pulsations of voltage in DC welding on reactance of welding circuit, conductivity of diodes of rectifier and stability of flashing process was studied. The phenomenon of overvoltages as a result of transition processes in welding circuit in flashing was explained. It was shown that at the same heating of specimens the consumption of electric power in DC welding is $15 \%$ higher than at alternating one. The macrorelief of flashing surface in DC welding is better by its quality than that at alternating one. 4 Ref., 1 Table, 10 Figures.
\end{abstract}

Key words: flash-butt welding, continuous flashing, direct current, alternating current, power parameters, high-frequency pulsations, technological characteristics

In the last decade the application of equipment for flash-butt welding (FBW) using sources of direct current has been widely spread. This was contributed by the new designs of powerful rectifiers, providing currents in welding circuit of machines of up to $100 \mathrm{kA}$ and higher. The most part of this equipment is designed for resistance welding (spot, projection ones). The application of direct current provides in this case a uniform loading of three phases of mains, and in some cases gives some technological advantages, in particular, more uniform distribution of current in the zone of heating of parts being welded and increase in efficient capacity generated in the welding zone.

These advantages are extremely important also in FBW, especially for parts with large cross sections and thicknesses of walls when high power is consumed calculated in hundreds of kilowatts-amperes. In industry the machines for FBW of $400-500 \mathrm{kV} \cdot \mathrm{A}$ capacity are successfully used providing currents in welding circuit of up to $80 \mathrm{kA}$ [1]. However, the field of their application is mainly limited with welding of rails. Here, as the basic technology the welding with interrupted preheating by resistance and the fol- lowing short-period flashing is used, for which not more than 10-15\% of the total energy input is consumed. In this case the application of direct current except of three phase loading of mains at a constant set power of $400-500 \mathrm{kV} \cdot \mathrm{A}$ allows considerable reducing of welding duration due to increase of current density during resistance preheating.

At the E.O. Paton Electric Welding Institute the technologies with continuous flashing without resistance preheating of parts of different steels and alloys with large cross sections of up to $100,000 \mathrm{~mm}^{2}$ and wall thickness of up to $100-$ $150 \mathrm{~mm}$, which are successfully implemented in industry (welding of pipes of oil-gas assortment of $50-1420 \mathrm{~mm}$ diameter with wall thickness of 5-30 mm, rails, metallurgical rolled metal). In welding of parts with large cross sections the task of increasing the power values at continuous flashing is also very urgent, especially in searching for possibilities of decreasing resistance of the secondary contour $Z_{\text {sh.c }}$. All the developed technologies of welding the parts with large cross sections using continuous flashing [2] are based on using equipment with a low resistance $Z_{\text {sh.c }}$, which provides excitement of flashing at low voltages and specific set power values.

The aim of this article is the comparative evaluation of power and technological charac- 
SCIENTIFIC AND TECHNICAL

Comparison of power characteristics in continuous FBW of steel plates of $25 \times 50 \mathrm{~mm}$ section using DC and AC power sources

\begin{tabular}{||c|c|c|c|c|c|c||}
\hline \hline Power source & $\begin{array}{c}U_{2 j}, \mathrm{~V} \\
\text { (op.c/welding) }\end{array}$ & $I_{2}, \mathrm{kA}$ & $Q_{1}, \mathrm{~kW} \cdot \mathrm{s}$ & $Q_{\mathrm{ex}}, \mathrm{kW} \cdot \mathrm{s}$ & $Q_{j}, \mathrm{~kW} \cdot \mathrm{s}$ & Efficiency factor \\
\hline $\mathrm{DC}$ & $6.7 / 4.7$ & $\frac{2.0-2.6}{2.3}$ & $\frac{1310-1509}{1414}$ & $\frac{1060-1241}{1148}$ & $\frac{929-1073}{1015}$ & $\frac{0.70-0.74}{0.70}$ \\
\hline $\mathrm{AC}$ & 6.8 & $\frac{1.6-2.1}{1.8}$ & $\frac{1052-1320}{1188}$ & - & $\frac{878-1054}{971}$ & $\frac{0.77-0.84}{0.80}$ \\
\hline $\begin{array}{l}\text { Note. } U_{2 j}-\text { secondary voltage on jaws (clamps) of welding machine (parts being welded); } I_{2}-\text { measured average current in the secondary } \\
\text { circuit for direct current and efficient for alternating current; } Q_{1}-\text { efficient power in the primary circuit of welding transformer; } Q_{j}- \\
\text { efficient power on jaws of welding machine (parts being welded); efficiency factor }=Q_{j} / Q_{1} .\end{array}$
\end{tabular}

teristics in welding of parts of low-alloyed steels using continuous flashing at direct (rectified) (DC) and alternating (AC) current. As the basic technology, welding the circumferential welds of pipes of modern pipelines using continuous flashing, thick-walled pipes of $1220-1420 \mathrm{~mm}$ diameter, $25 \mathrm{~mm}$ thickness of steels of strength class X70-X80 was used. The typical program of changing the main parameters in FBW of such pipes is given in Figure 1. The multi-year experience of developments of technologies of pipe welding shows that specific power values remain similar both in flashing along the entire area of pipe section, and also in its separate sectors cut out around the perimeter of pipe. Therefore, welding of specimens of $25 \times 50 \mathrm{~mm}$ section, cut out from a pipe, using the DC and AC source was performed at the following modes:

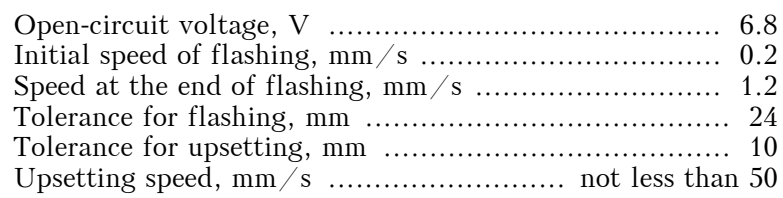

The edges of specimens, the same as in welding of full-scale pipes, had edges bevel to provide the flashing excitement. Here unlike welding of pipes the change in speed of flashing $v_{\mathrm{fl}}$ to detect

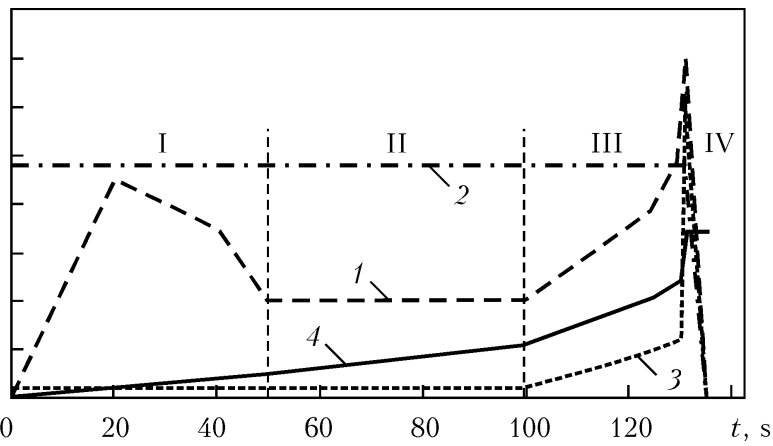

Figure 1. Typical program of change of main parameters in welding of pipes with $25 \mathrm{~mm}$ wall thickness: I - fusion of edges bevel (flashing excitement); II - heating; III accelerated flashing; IV - upsetting; 1 - current; 2 voltage; 3 - speed; 4 - movement (cyclograms are identical for DC and AC) the periods of possible unstable flashing was preset strictly according to the program without its automatic correcting.

As the basis of accepted methods for conductance of experiments the similarity of technology, equipment and accompanied processes in welding of batches of specimens at alternating and direct current was taken. The welding in both cases was performed in universal machine K724 of design of the E.O. Paton Electric Welding Institute with the transformer of $150 \mathrm{kV} \cdot \mathrm{A}$ capacity. After welding of batches of specimens in it at the frequency of $50 \mathrm{~Hz}$, welding transformer was removed and three-phase rectifier of «RoMan» company of $180 \mathrm{kV} \cdot \mathrm{A}$ capacity was connected to the welding circuit. The impedance of machine after its re-equipping using rectifier was preserved $Z_{\text {sh.c }}=240 \mu \mathrm{Ohm}$ (measured at the frequency of $50 \mathrm{~Hz}$ ), effective resistance of $96 \mu \mathrm{Ohm}$.

During flashing of specimens the control of temperature in HAZ was carried out.

All the welded specimens were tested according to the API International standards. The parameters of welding process were recorded and calculated using computer system and software designed by the authors of the article. The frequency of inquiry of each channel of measurement of current and voltage was $10 \mathrm{kHz}$. The results of experiments are given in the Table.

In both cases the average power consumption $Q_{j}$ used for heating does not exceed $5 \%$, which evidences of high stability of processes of metal heating. The intensity of heating sources is also featured by stability, which is confirmed by measurements of temperature fields in welding of specimens of test batches (Figure 2). In DC welding the temperature of both welded test specimens was measured. The temperature fields of zones of heating of the parts, being cathode and anode in flashing, were not much different, which can be predetermined by additional influence of arc discharges generated after fracture (explosion) of local contacts. However, these differ- 


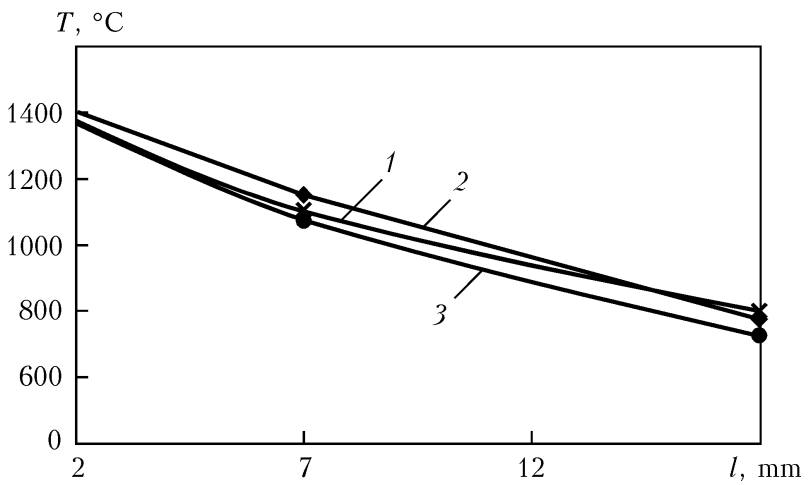

Figure 2. Distribution of temperature in welding zone during flashing before upsetting: 1 - heating using alternating current; 2, 3- heating anode and cathode using rectified current, respectively

ences can not considerably influence the quality of welding because of their small value.

The general power consumption $Q_{1}$, consumed in welding from mains is by $15 \%$ higher in flashing at direct current, and efficiency factor is relatively lower than in flashing at alternating current. Relatively low efficiency factor at direct current is predetermined by sufficiently high resistance of diodes in welding circuit, which leads to additional power losses.

It should be noted that use of high power rectifiers for FBW is not very rational from the economic point of view as compared with the resistance welding. Figure 3 shows the typical characteristic of modern rectifies for the resistance welding. The admitted values of current depend greatly on relative duty cycle and duration of welding current $t$. Such rectifiers are the most power-saving in using at strictly limited duty cycle, being not more than 10-15\%. At duty cycle equal to $20 \%$ the admissible currents are 1.7-2 times reduced. Most machines for spot and projection welding are operating almost in the same mode. During their use for resistance welding when duty cycle reaches $30-50 \%$, the admissible currents are 2.2-2.8 times decreased. Respectively, it becomes necessary to increase the capacity of rectifiers and create cooling systems for them, thus complicating the equipment and increasing the power losses.

According to the procedures of works after welding of two batches of specimens on the base mode it was supposed to perform the separate DC welding at lower voltage $U_{2 \text { op.c }}=6.5 \mathrm{~V}$ to reveal the influence of resistance $Z_{\text {sh.c }}$ in DC welding. However, at decrease of voltage by less than $6.8 \mathrm{~V}$ the stable flashing process was not managed to be obtained, as a result of short circuiting of edges the flashing interrupted. The dependencies, characterizing the changes of voltage on clamps of current conducting jaws and

$$
I_{\mathrm{w}}, \mathrm{kA}
$$

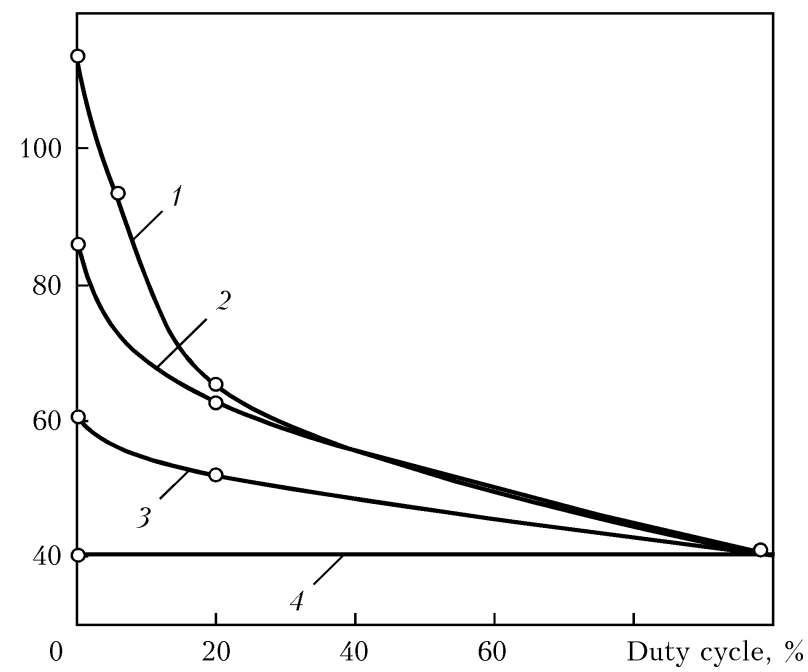

Figure 3. Dependence of current of loading on duty cycle at $t=0.06$ (1), 0.1 (2), 1 (3) and more than 2 (4) $\mathrm{s}$

efficient power, which is generated in contact between the parts [3], are given in Figure 4. From their comparison it is seen that maximum efficient power generated in the contact is approximately the same in both cases and the drops of voltages at the loads close to $15 \mathrm{kA}$ have also the close values. Therefore, the limits of possible admissible increase of conductivity are close. The margin of increase of stability of flashing process at direct current is exhausted by drop of voltage by $2 \mathrm{~V}$ even at the initial period of load current increase. Actually, the flashing process is proceeding at the lower drop of voltage at spark gap than at alternating current. At this area the dynamics of increment of power with increase in conductivity of spark gap is also lower than at

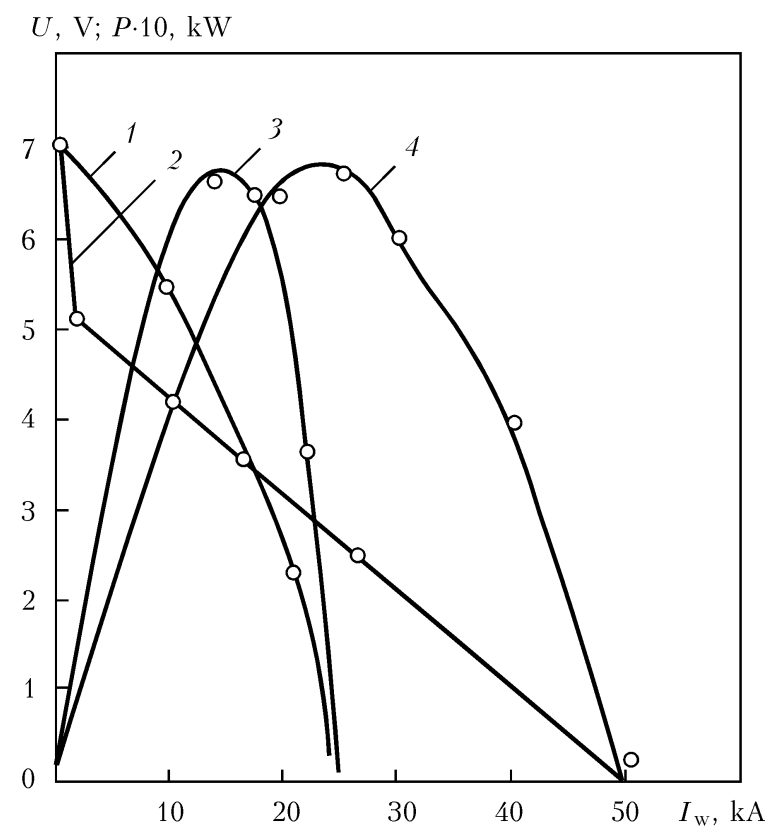

Figure 4. Dependences of voltage $(1,2)$ and power $(3,4)$ on current in welding circuit respectively at alternating (1, $3)$ and direct $(2,4)$ current $\left(U_{\text {op.c }}=7 \mathrm{~V}\right)$ 

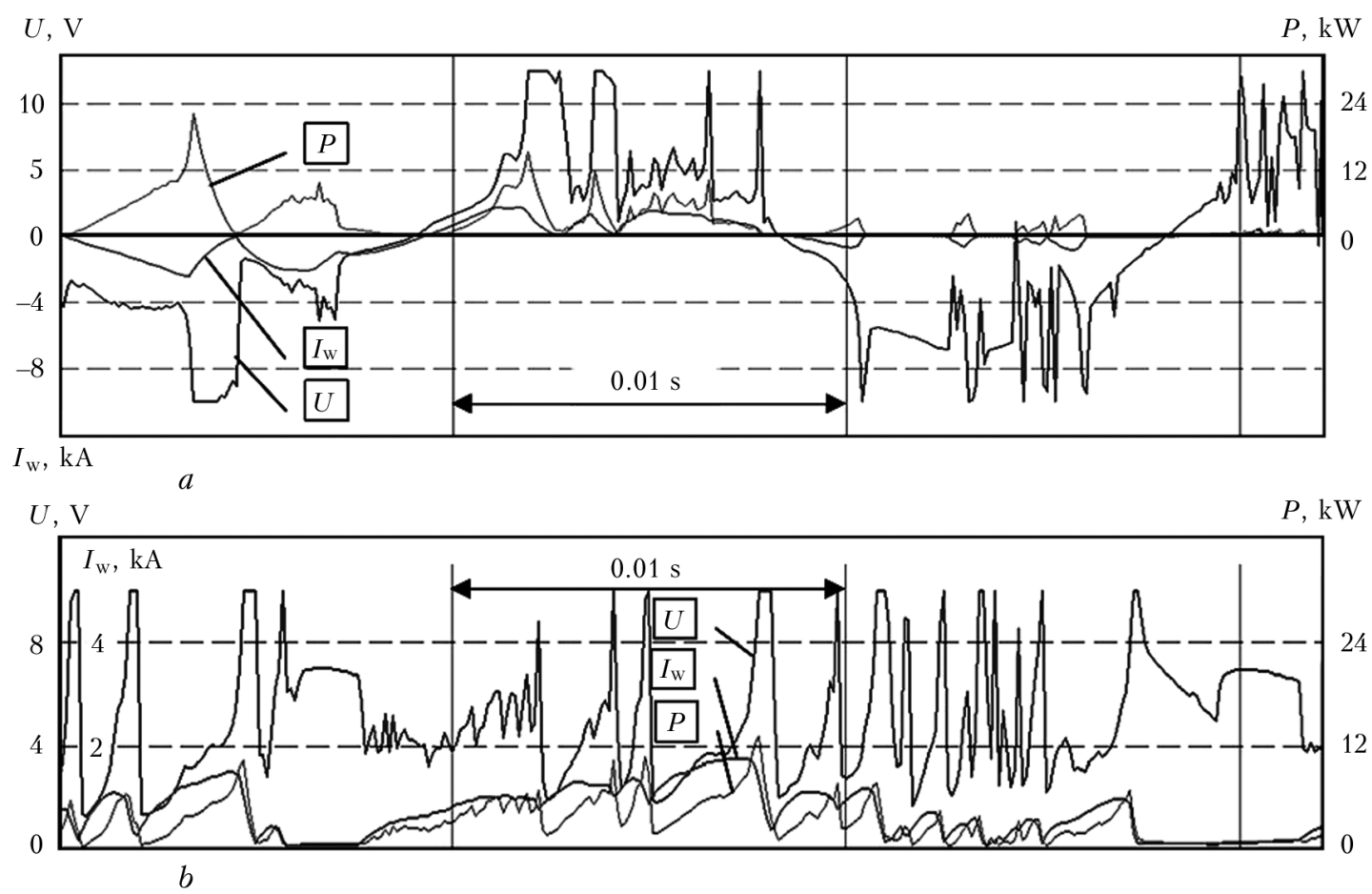

Figure 5. Oscilogram of welding current, voltage and power generated for heating in flashing in the period II at alternating (a) and direct (b) current

alternating current, which does not facilitate the increase of stability of flashing process. The mentioned drop of voltage on diodes is characteristic and inseparable feature of change in their conductivity under load.

The recording of flashing process of specimens at direct and alternating current in the flashing period II is given in Figure 5. Such flashing process is considered to be stable, where there is no long break ups in passing of current and short circuits, at which the current is several times increased in relation to the average values of current in flashing. Such evaluation is quite conditional as far as the process of continuous flashing is interruptive as to its nature. Small interruptions $(0.02-0.03 \mathrm{~s})$ and short-period increase of current, classified as short circuits of $0.01-0.02 \mathrm{~s}$ duration, does not considerably influence the stability of heating and process stability. In this case these data can be used in comparative quality evaluation of process at different stages of its realization according to the program.

The most critical from the point of view of probable violations of process are periods I and III of the program. In the period I the probability of short circuits, when the process of flashing is interrupted, is the highest. Therefore, most often in welding using flashing, including pipes using the program given in Figure 1, the controllers are used, which automatically decrease the speed of flashing and eliminate short circuits. In the process of welding of test batches of specimens such controllers were not used, which allowed revealing the potential possibilities of DC and $\mathrm{AC}$ sources to the greater extent. The most critical from the point of view of influence of stability of flashing on the quality of joint is the period III of the program. Even negligible interruptions and short circuits, not exceeding the fraction of a second, in the period preceding upsetting can result in formation of non-quality joints.

The results of analysis of recording of flashing process at all the stages of the program are given in Figure 6. In the period II of flashing the duration of pauses in passing of current is almost $10 \%$ higher at alternating current as compared to direct one. With increase of flashing speed in the period III at direct current the 1.5-1.8 times higher increase of duration of periods of short circuits is observed than that occurring at alternating one, which evidences of decrease of margin of stability of flashing process before upsetting.

The characteristic feature of oscillograms in FBW is the presence of pulses of high frequency at voltage and current curves (see Figure 5). It is assumed that they are formed at explosions of elementary contacts and can serve as a criterion for evaluation of their number. In work [2] it is shown that pulsations occur during melting of single contacts of large area when their overheating is observed accompanied with boiling and explosion-like evolutions of metal vapors. Their duration is considerably shorter than the real time of heating of contacts of sufficiently large 


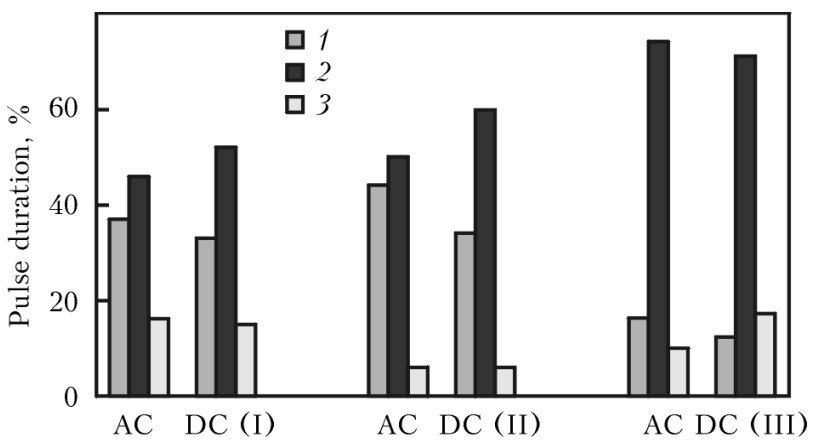

Figure 6. Diagram of relations of duration of interruptions in passing of current (1), short circuits (2) and pulses of current in flashing (3)

area, forming the relief of flashing surface. Pulses of high frequency are differed by amplitude values, duration and depend on the flashing period. The average frequency of pulsations is growing with heating of parts in flashing process, and also in the final period of flashing before upsetting. At the comparable frequency of pulses of welding voltage the number of pulses at direct current almost 2 times higher than at alternating one. It is connected with the fact that flashing and spark formation are excited at instant values of voltage at the clamps after reaching the level of more than 3-4 V. If more than a little of a half of sinusoid corresponds to this condition at alternating current (see Figure 5, $a$ ), then at direct current it is always fulfilled (see Figure 5, b).

As is seen from the records of welding voltages made using digital oscillograph (Figure 7) the amplitude of pulses for direct current is by minimum $25 \%$ higher than that for alternating one, and their duration is relatively shorter. To explain this phenomenon of overvoltages and evaluation of electric parameters of pulses on the oscillogram of voltage on the jaws of FBW machine, let us study the electric diagram of model of welding process at direct current given in $\mathrm{Fi}$ gure 8. Let us neglect the effective resistance of secondary contour and then consider the source $e$ as a DC source.

At the absence of diode $D$ and short circuit of key $K$ we will have a transition from the mode of open circuit to the mode of flashing, then the total voltage $U$ on the resistors and duration of transition process $\tau$ :

$$
U \approx e(1-0.99 \exp (-t R / L)), \quad \tau=L / R .
$$

At disconnection of key $K$ we will have a transition from the mode of flashing to the open circuit mode:

$$
U \approx e(1+100 \exp (-t 101 R / L)), \quad \tau=L / 101 R .
$$

Thus, the jump of voltage at jaws of welding machine at interruption of contact and transition

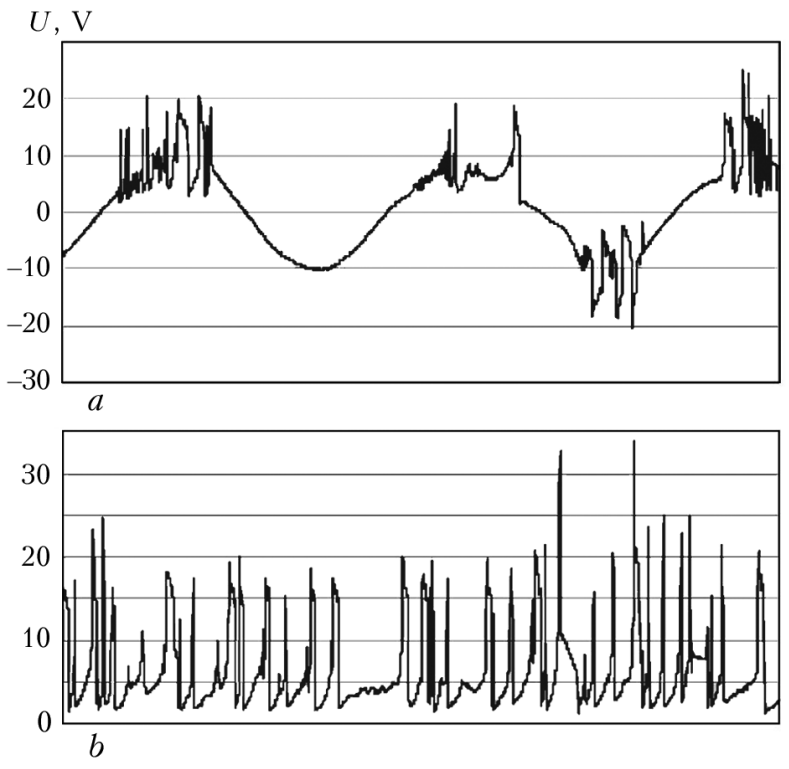

Figure 7. Voltage at jaws of FBW machine with AC (a) and DC (b) source at $t=50(a)$ and $25(b) \mathrm{ms}$

to the open circuit is considerably higher than at appearance of contact (in our example the correlation is $100 / 0.01$ ); the duration of pulses or time of transition process is much shorter than in reverse transition (in our case 1/100).

Due to a very short duration of transition process $\tau$ one can assume also that the spectrum of these pulses is composed of high-frequency harmonics, at which the rectifying diodes lose their properties on rectifying and resistance of diode is significantly increased. It results in great values of amplitude of pulses at direct current as compared to alternating current.

As a result of high-frequency pulsations of voltages the influence of reactivity of welding circuit in DC welding is obvious.

It follows from the given data that a part of pulses of high frequency, observed on oscillograms in DC welding, is not directly connected with melting of single contacts and is a consequence of influence of reactance of welding circuit in DC welding. Alongside, during the comparative analysis of shape of curve of voltage and

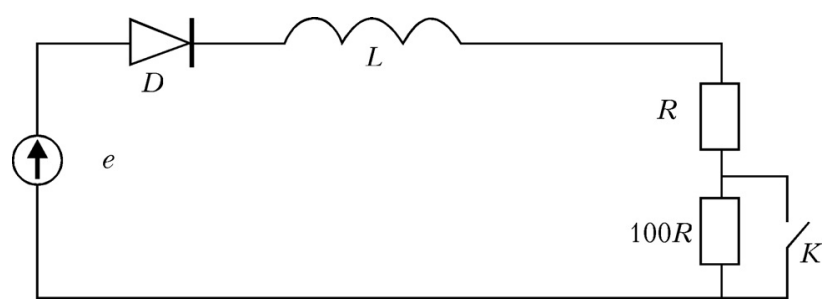

Figure 8. Electric circuit of model of flashing process at direct current: $e$ - voltage at the input of secondary circuit of welding machine (output of power transformer); $D-$ rectifying diode in the DC source; $L$ - inductance of secondary circuit; $R$ - conditional resistance of parts in flashing; $100 R-$ conditional transition resistance of flashing parts at transition from the mode of flashing to the open circuit mode 

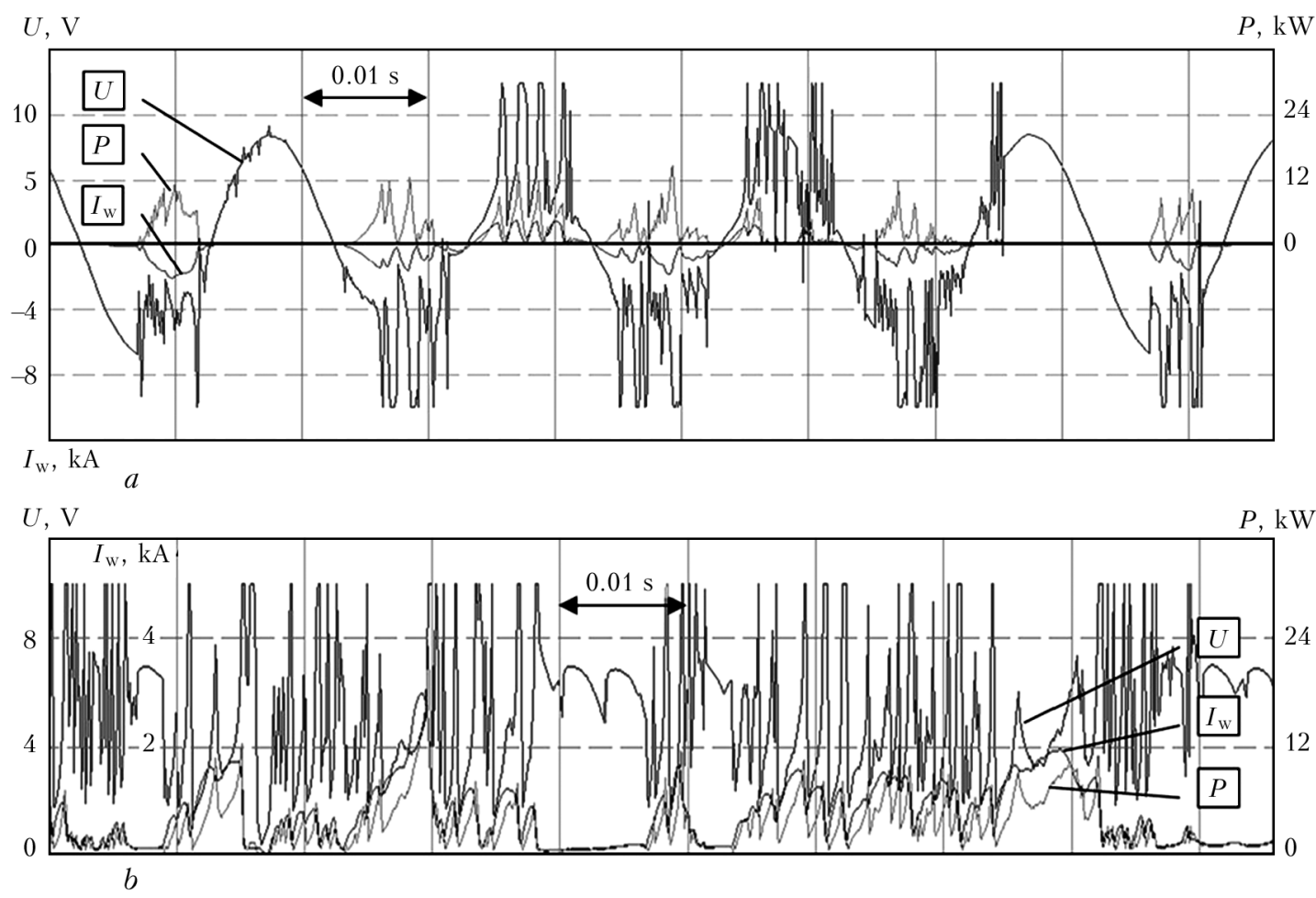

Figure 9. Oscilogramm of welding current, voltage and power at alternating $(a)$ and direct $(b)$ current at flashing before upsetting

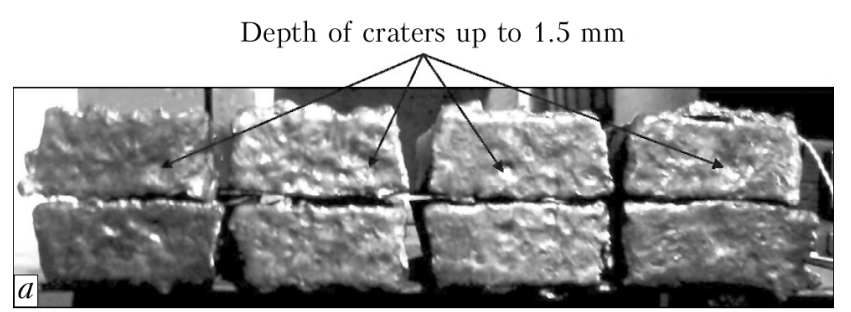

Depth of craters up to $1.0 \mathrm{~mm}$

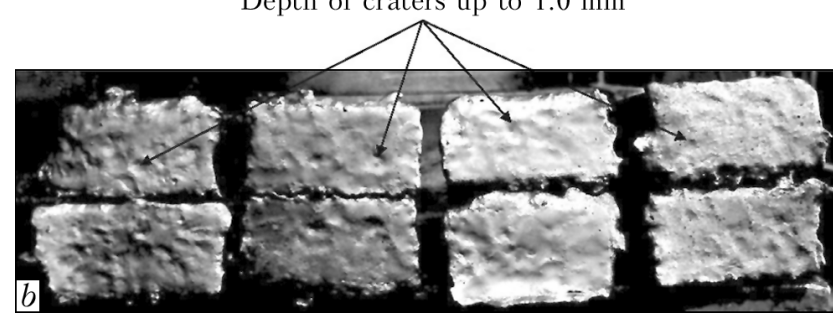

Figure 10. Surface of flashing of specimens after interruption of the process before upsetting at alternating $(a)$ and direct $(b)$ current

current at direct current the attention should be paid to pulsations of voltage and current of sufficiently long duration accompanied by increase of efficient consumed power. The similar pulsations are observed in AC flashing. As is seen from oscillograms taken in the period preceding the upsetting (Figure 9), it is possible to distinguish the separate pulses of a higher duration (more than $2 \mathrm{~ms}$ ) from the pulses of current of increased frequency, at which increase of efficient power is observed. There is bigger number of such pulses in flashing at alternating current. The interruption of flashing process in these periods allowed establishing that the maximum depth of craters, formed at the surface of flashing at direct current, amounts to 1.0 and at alternating one is $1.5 \mathrm{~mm}$ (Figure 10).

The mentioned distinctions in formation of flashing surface did not have influence on quality of joints, which is proved also by other investigations [4] obtained during flashing of thinwalled products. Thus, during flashing at direct current more flat surface of flashing is formed and the probability of formation of different defects in plane of a joint is lower. The mentioned distinctions in formation of flashing surface did not have influence on quality of joints of specimens produced at alternating current according to the similar mode.

The carried out comprehensive mechanical tests of batches of specimens, welded at the given mode at alternating and direct current, proved their complete correspondence to the requirements of the standard.

\section{Conclusions}

1. Application of direct current in FBW using continuous flashing of thick-walled parts of lowalloyed steels does not give essential advantages, which could be expected in connection with decrease of resistance of welding circuit, in particular, to obtain stable flashing at lower open-circuit voltages. 
2. To the number of characteristic features of DC flashing process the reduction of duration of interruptions in passing of current in flashing and also increase of frequency and amplitude of pulsations of voltage and current, resulted by boiling of metal, should be referred. It is shown that this feature of the process is predetermined by change in conductivity of diodes of rectifier in the specified spectrum of high-frequency harmonics of welding current.

3. In DC flashing some decrease of depth of craters at the surface of flashing is observed. In welding of test batches of specimens at the same modes at direct and alternating current the stable quality of joints was obtained corresponding to the standard requirements, which evidences of negligible influence of this process parameter on quality of joints of the mentioned thickness. Obviously, its positive influence on formation of joints can be expected in welding of parts of large thickness (50 $\mathrm{mm}$ and more).

4. In welding at direct current the total power consumption is by $15 \%$ higher than at alternating current, and the efficiency factor is relatively lower ( 0.7 at $\mathrm{DC}$ and 0.8 at $\mathrm{AC})$, which is predetermined by additional losses of power in rectifiers.
5. The intensity of heating sources at direct and alternating current is almost the same. In welding at the same modes the similar heating of metal in HAZ is provided necessary for formation of the quality joints.

6. During re-equipping of $\mathrm{FBW}$ machines from alternating to direct current the necessity of repeated increase of number of modules of DC rectifier as compared to the similar re-equipping of machines for spot and projection welding should be taken into account. This considerably increases its cost and operation costs, in particular, connected with cooling of diodes.

1. Kuchuk-Yatsenko, S.I., Nejlo, Yu.S., Gavrish, V.S. et al. (2010) Prospects of increasing energy characteristics of flash butt welding (Review). The Paton Welding J., 2, 23-27.

2. Kuchuk-Yatsenko, S.I. (1992) Flash butt welding. Kiev: Naukova Dumka.

3. Kuchuk-Yatsenko, S.I., Rudenko, P.M., Gavrish, V.S. et al. (2010) Energy characteristics of the processes of flash-butt welding at alternating at direct currents. The Paton Welding J., 12, 22-26.

4. Sidyakin, V.A., Orlov, B.D. (1969) Flash-butt welding of thin-walled parts at direct current. Svarochn. Proizvodstvo, 9, 22-24. 